\title{
Chaucer como poeta de amor cortés y su contraste con Shakespeare en Troilus and Criseyde
}

Rosario FARAUDO

Universidad Nacional Autónoma de México

Al analizar el legado de Chaucer, Harold Bloom lo reconoce como el primero de los escritores en lengua inglesa, exceptuando a Shakespeare (1994: 99). Los cuentos de Canterbury, con su maravillosa variedad de personajes y su profunda visión de la naturaleza humana, han constituido un acervo para la creación literaria a través de los últimos seiscientos años. Sin embargo, en su época, Troilus and Criseyde, una obra poco leída en la actualidad, fue considerada por el mismo Chaucer como su mayor logro. Sin subestimar los Cuentos, se puede decir que la calidad poética de esta obra justifica este concepto, por lo menos en opinión de C. S. Lewis (1958: 176).

No se pretende en este espacio llevar a cabo un análisis profundo de la obra y sus personajes como hizo, de manera magistral, C. S. Lewis en The Allegory of Love, publicado en 1936. Se trata únicamente de presentar algunos detalles que llaman la atención del lector del año 2003 y observar el contraste existente con el trato que le da Shakespeare al mismo tema, con la esperanza de despertar interés por la lectura de estas dos grandes obras literarias.

Las fuentes de esta historia se remontan a la "materia de Troya" y en especial al francés Benoît de St. Maure y su Roman de Troye que apareció en el siglo XII. Guido delle Colonne, un juez siciliano, la tradujo al italiano bajo el título de Historia Trojana, en la que se inspiró Boccaccio para su novella-poema Il Filostrato.

El poema de Chaucer se asemeja a "The Knight's Tale" de Los cuentos de Canterbury en que ambos tienen sus fuentes inmediatas en Boccaccio y tratan material de los antiguos ciclos del romance. Aunque aparecen en el Troilo algunos personajes importantes de La Ilíada, Homero casi no menciona a nuestros protagonistas - Troilo, Criseyda y Pándaro- y aun a Troilo, hijo de Príamo, le da muy poca importancia. St. Maure inicia su relato con la separación de los amantes, al partir Criseyda de Troya, y constituye solamente un episodio en medio de un poema larguísimo. Boccaccio lo convier- 
te en una "novella" renacentista, que Chaucer posteriormente transforma en un poema de amor cortés. Con el correr de los años, Shakespeare retomaría este tema para producir un drama lleno de amargura, que forma parte de los llamados "problem plays". Esta obra se comentará más adelante.

En la obra de Boccaccio el autor se identifica con Troilo, como el amante rechazado, y a través del relato expresa su propia pasión por Maria d'Aquino. Chaucer, en cambio, se distancia de la historia interponiendo un narrador. $\mathrm{Al}$ invocar a Tisifone, una de las Furias, prepara el ambiente para una historia trágica de amor y traición, dicho en sus propias palabras, "Thise woful vers, that wepen as I write" (1.7). También se encomienda a Dios, a la manera cristiana, para poder llevar a cabo su labor. Aunque la invocación de las musas es propia de la poesía de todas las épocas, en esta obra parece haber una fusión de cristianismo y helenismo. Desde luego, abundan las referencias a los dioses griegos, especialmente Venus y todos aquellos relacionados con el amor y con la guerra, pero por otro lado, el discurso de los personajes con frecuencia se dirige a Dios en singular y a la manera cristiana, como se hubiera hecho en la época de Chaucer. Un ejemplo lo encontramos cuando Troilo se encomienda a Venus al disponerse a entrar en la alcoba donde duerme Criseyda, y al sorprenderla Pándaro, éste le suplica: "No word, for love of God, I yow biseche!" (3.755).

Chaucer elimina algunas de las frivolidades renacentistas de la obra de Boccaccio y medievaliza a los personajes de la literatura clásica, otorgándoles un comportamiento propio de caballeros y damas medievales. Persisten, no obstante, algunos elementos de influencia italiana, tales como un soneto de Petrarca (núm. 88), traducido en la canción de Troilo.

Un elemento que inclusive va más allá del Renacimiento y nos transporta a la poesía de John Donne, es la irreverencia con que los amantes se dirigen al nuevo día que los sorprende después de su primera noche de amor: "Envyous day, what list the so to spien? / What hastow lost, why sekestow this place (3.1454) [...] What profrestow thi light here for to selle? / Go selle it hem that smale selys grave; / We wol the nought, us nedeth no day have" (3.1461). "And ek the sonne, Titan, gan he chide, / And seyde, 'O fool, wel may men the dispise, / That hast the dawnyng al nyght by thi syde, / And suffrest hire so soone up fro the rise,..." (3.1466). Hasta los amantes de la poesía de Donne debemos reconocer en este antecedente una relación estrecha con el tono del poema del último, "The Sun Rising" (1633):

Busy old fool, unruly sun,

Why dost thou thus,

Through windows and through 
curtains call on us?

Must to thy motions lovers' seasons run?...

Por otro lado, como es frecuente en la lírica medieval, no falta el canto a la belleza natural, propicia al amor: "In May, that moder is of monthes glade / That fresshe floures, blew and white and rede / Ben quike agayn, that wynter dede made / And ful of bawme is fletyng every mede / Whan Phebus doth his bryghte bemes sprede..." (2.50).

De acuerdo con la tradición del "amor cortés", Troilo es un caballero valiente y arrojado en la batalla, pero su vida depende de que la dama, Criseyda, lo acepte como su servidor. En su primera entrevista, organizada por Pándaro, Troilo le ofrece a Criseyda estar siempre a su servicio, cosa que más adelante hará el griego Diomedes, como es propio de la tradición. Al aceptar Criseyda a Troilo como su caballero, pone por condición la protección de su honor, y le advierte, también siguiendo lo que dicta el amor cortés, que ella mantendrá la soberanía en el amor aunque él sea hijo de un rey. A diferencia de Shakespeare, Chaucer nos ofrece una imagen muy positiva de Criseyda, como una viuda virtuosa, respetable y de gran belleza: "Nas nevere yet seyn thyng to ben presed derre / Nor under cloude blak so bright a sterre / As was Criseyde, as folk seyde everichone / that hir behelden in her blake wede" (1.175).

La consumación del amor no era indispensable dentro del amor cortés, aunque era frecuente y tolerado, por lo menos en la literatura. En una sociedad donde había que buscar el amor fuera del matrimonio, el secreto era un elemento indispensable, cosa que estos amantes cuidan rigurosamente. Troilo logra convertirse en amante de la dama con ayuda de Pándaro, tío de Criseyda, pero no sin antes tener que vencer cierta resistencia. Lo anterior eliminaría algunas objeciones de tipo moral, puesto que en este caso lo que había que proteger era el honor y no la virginidad. C. S. Lewis opina que Chaucer sanciona el amor entre Troilo y Criseyda como si se tratara de un matrimonio y que, por lo tanto, la falta de Criseyda está en traicionar a Troilo con Diomedes, no en haber aceptado al primero como amante (1958: 189-197). Chaucer parece relatar la traición de Criseyda muy a su pesar, como obligado por el autor original del cuento, y se disculpa con las damas por tener que hacerlo: "Bysechyng every lady bright of hewe, / and every gentil womman, what she be, / That al be that Criseyda was untrewe, / That for that gilt she be nat wroth with me" (5.1772).

El Libro III contiene poesía erótica de insuperable valor. El narrador nos cuenta cómo Troilo acaricia a Criseyda, se besan, se abrazan, cómo van cayendo el uno en brazos del otro y lo mucho que lo disfrutan. En opinión 
de C. S. Lewis, esta poesía constituye una lección sobre, "how Chaucer can so triumphantly celebrate the flesh without becoming either delirious like Rossetti or pornographic like Ovid" (197).

El narrador interviene en determinados momentos intercalando opiniones o comentarios, ya sea para anticipar cualquier posible crítica a su heroína por enamorarse de Troilo demasiado aprisa, como sucede en el Libro II, o como hace en el Libro III para reflexionar sobre el problema del escritor que debe seleccionar los incidentes para que su relato no sea tedioso. De nuevo Chaucer se distancia de la narración mencionando el hecho de que su fuente, "myn autour", no ha incluido todos los detalles, por lo tanto, él tampoco podría hacerlo aunque quisiera: "For sothe, I have naught herd it don er this / In story non, neno man here, I wene; / And though I wolde, I koude nought, ywys;..." (3.498). En mi opinión, sin duda la intervención más interesante del narrador es la que se refiere a los cambios del lenguaje. En la introducción al Libro II, después de invocar a la musa, Chaucer se excusa por no escribir en latín sino en su propia lengua, y refrenda su distancia de la narración al observar que él solamente cuenta lo que dice su autor, haciendo hincapié en las transformaciones que sufren las lenguas a través de los años: "Ye knowe ek that in forme of speeche is chaunge / Withinne a thousand yeer, and wordes tho / That hadden pris, now wonder nyce and straunge / Us thinketh hem, and yet thei spake hem so, / And spedde as wel in love as men now do..." (2-22). A seiscientos años de distancia y dada la dificultad que enfrentamos los lectores actuales al empezar a leer el inglés de Chaucer, se corrobora la validez y la trascendencia de esta preocupación.

Existe un gran contraste entre este poema y la versión que más tarde nos ofrecería Shakespeare del mismo asunto. Chaucer escribe un poema de amor, apegado a los cánones del amor cortés, mientras que en su Troilus and Cressida, Shakespeare presenta el lado oscuro de la humanidad, en un drama donde la problemática de los enamorados viene siendo secundaria. Se ha dicho que esta obra tiene cierta afinidad con algunos de los sonetos, sobre todo los que se relacionan con la "dama morena". En este drama no encontramos héroes ni heroínas. Podría decirse que Shakespeare utiliza toda la exuberancia de su lenguaje y su imaginación para analizar a políticos, reyes, damas y caballeros de su tiempo, y como acostumbra suceder con este autor, de todos los tiempos.

En la obra de Shakespeare los conflictos al interior de Troya y especialmente dentro del campamento griego tienen un papel preponderante y el autor les adjudica escenas muy importantes. Al no estar limitado por la ética cristiana - puesto que sus personajes son paganos-, Shakespeare explora el comportamiento político con entera libertad. Es una obra donde nadie se 
hace ilusiones respecto a la causa que están defendiendo. Ambos lados comprenden que la guerra en la que están peleando no está justificada y lo expresan con frecuencia. Entre los troyanos se considera la devolución de Elena y tanto unos como otros se refieren a ella como una prostituta y a Menelao como un cornudo. Hablando de su comandante Menelao, Ulises le dice a Patroclo: "we lose our heads to gild his horns" (IV, v).

Ulises aparece más como villano que como héroe, personificando al político manipulador. Para favorecer sus propósitos habla del principio jerárquico que gobierna al mundo, invocando toda la cosmogonía medieval, que en la tierra tiene su paralelo en las clases y los rangos. No hay que olvidar que el que habla es el autor, que en este discurso refleja el pensamiento de su época. Héctor es un personaje anacrónico. Aparece como un caballero medieval, un tanto caprichoso, que con toda su nobleza sucumbe ante la cobardía de Aquiles que lo asesina cuando lo encuentra desarmado. Su muerte, por lo tanto, no es heroica.

En general, tanto griegos como troyanos están caracterizados con un tinte muy negativo. En la obra de Chaucer, los griegos, con excepción de Diomedes, casi no aparecen y aun los troyanos participan de manera limitada, podría decirse que se encuentran solamente en el trasfondo. El lenguaje que utiliza Shakespeare es directo desde el Prólogo, 'Menelaus' queen, with wanton Paris sleeps", y con frecuencia es obsceno. Abundan las imágenes sexuales y los juegos de palabras con implicaciones eróticas.

La personalidad de las dos protagonistas, Cryseida y Cressida, tiene pocas características comunes, excepto el hecho de encontrarse ambas en una posición delicada en una ciudad sitiada. En opinión de Harold Bloom, tanto Chaucer como Shakespeare sienten "admiración afectuosa" por sus heroínas, si bien en el caso de Shakespeare se trata de una admiración más bien lujuriosa (1998: 334). Aunque a simple vista podría pensarse que Shakespeare no favorecía mucho a su Cressida, si tomamos en cuenta que se trata de una mujer del Renacimiento, aunque su autor la coloque en Troya, ya no parece tan extraña la opinión de Bloom. Pensemos por un momento en la angelical Desdémona, que también es una mujer atrevida y dotada de un diálogo muy ingenioso. $\mathrm{Si}$ Chaucer hace que sus griegos y troyanos se comporten como damas y caballeros medievales, es lógico suponer que Shakespeare también adapte sus personajes a su propia época. La Cressida de Shakespeare es una mujer hábil y mundana que acepta a Troilo como amante sin mucha resistencia, de manera voluntaria y consciente. Las intrigas de Pándaro no la engañan como a Criseyda, puesto que conoce bien a su tío y se da perfecta cuenta de lo que éste persigue: "By the same token, you are a bawd" (I, iii, 813). Su discurso dista mucho de ser recatado y tierno como el de la heroína de Chaucer. 
En Shakespeare, el diálogo entre los futuros amantes implica más deseo que amor. Cuando Troilo le dice "This is the monstuosity in love, lady -that the will is infinite and the execution confined; that the desire is boundless and the act a slave to limit", la respuesta de ella está en el mismo plano: "They say all lovers swear more performance than they are able, and yet reserve an ability that they never perform: vowing more than the perfection of ten and discharging less than the tenth part of one. They that have the voice of lions and the act of hares, are they not monsters?" (III, ii, 825).

Esta Cressida ha visto mucho, desconfía hasta de sí misma y ve a los hombres con escepticismo.

Así como Chaucer describe la relación de los amantes con una serie de detalles eróticos que ya se comentaron, el contexto en el que se desenvuelve la relación de Troilo y Cressida es un tanto sórdido. Al finalizar una primera entrevista en que ambos se declaran su amor, Pándaro literalmente los lleva a la cama sin más: "Whereupon I will show you a chamber and a bed; which bed, because it shall not speak of your pretty encounters, press it to death: away!" (III, iii, 826). Pándaro ha procurado a Cressida como una mercancía, y como tal acaba siendo tratada por los troyanos.

Troilo resulta un personaje poco caballeroso, que más parece estar enamorado del amor y desear a Cressida como objeto sexual. Cuando su "amada" se ve obligada a abandonar la ciudad, este Troilo no piensa ni por un momento en salvarla. Nos inspira piedad en la escena donde espía —con ayuda de Ulises- la cita de Cressida con Diomedes y confirma sus sospechas acerca de la traición de su dama. A pesar de esto, su discurso se niega a aceptar la realidad: "This is she?- No, this is Diomede's Cressida / If beauty have a soul, this is not she..." $(\mathrm{V}, \mathrm{ii}, 840)$.

La figura de Pándaro ha sido con frecuencia comparada con la Celestina, pero hay que tomar en cuenta que el primero no recibe dinero por sus servicios. En el caso de Chaucer, se trata del hombre práctico, que disfruta organizando y manipulando a los demás; es el hombre que hace que los proyectos se cumplan. Es un buen amigo, ingenioso, dispuesto a ayudar a Troilo de buena fe ya que no considera que la relación con él perjudique en nada a su sobrina. En algunos momentos resulta cómico y hasta ridículo, pero de manera simpática. Por su comportamiento en sociedad parece ser un hombre ameno que deleita a sus amigos. C. S. Lewis lo considera, además de un puente entre Troilo y Criseyda, un puente entre el romance y la comedia (1958: 197). El Pándaro de Shakespeare, aunque comparte algunas características con el de Chaucer, es un personaje mucho menos afortunado: si bien su discurso es muy ingenioso, como se aprecia en sus diálogos con Elena y con Cressida, es mucho más cínico que el de Chaucer, es sifilítico y 
acaba siendo rechazado por Troilo al terminar la obra. Pándaro es el encargado de despedirse del público. No existe evidencia de que esta obra haya sido representada en época de Shakespeare, y es muy dudoso que semejante insulto hubiera sido aceptado por el público, por muy sofisticado que éste fuera: "As many as be here of Pandar's hall, / Your eyes, half out, weep at Pandar's fall, / Or if you cannot weep, yet give some groans, / Though not for me, yet for your aching bones... Till then I'll sweat and seek about for eases, / And at the same time bequeath you my diseases" ( $\mathrm{V}, \mathrm{xi}, 845)$.

Lo que sí comparten estos tres personajes, tanto en un autor como en otro, es su conciencia de ser personajes de la historia literaria. En ambas obras hay un momento en que los amantes se juran amor eterno y proclaman que en caso de fallar, pasarán a la historia como emblemas de constancia uno y de traición la otra. De la misma manera los intermediarios serán siempre considerados como "pandars".

Shakespeare se abstiene de moralizar mientras que Chaucer disculpa las faltas de sus protagonistas. El poema de Chaucer, a pesar del final trágico, termina con una nota optimista, con la imagen de Troilo, después de su muerte, minimizando las angustias de la tierra, y al mismo tiempo, con la voz del narrador, recomendando la sublimación del amor a lo divino y condenando al paganismo. Una vez más el autor se coloca dentro de su propia época. Por otra parte, Shakespeare sostiene el mismo tono negativo hasta el final de la obra: Troilo expresa una gran amargura y todo el odio acumulado contra los griegos, así como su deseo de vengar la muerte de Héctor. Como ya se ha mencionado, las palabras finales corren a cargo de Pándaro, que acaba de ser rechazado por su amigo.

Ambas obras, sin embargo, tienen una gran afinidad que va más allá de la historia básica, el género literario y el tono: sus autores utilizaron de manera brillante los recursos de su lengua para lograr dos obras de arte que han sobrevivido a través de los años, y cada una en su estilo tiene validez permanente.

\section{Bibliografía}

Bloom, Harold. 1994. The Western Canon. Nueva York: Riverhead Books.

Riverhead Books,

Chaucer, Geoffrey. 1957. Troilus and Criseyde, en The Complete Works of G. Chaucer. Ed. de F. N. Robinson. Oxford: Oxford University Press. 
Donne, John. 1973. "The Sun Rising”, en The Literature of Renaissance England. Ed. de John Hollander y Krank Kermode. Londres: Oxford UP. Vol. 2 de The Oxford Anthology of English Literature. 4 vols.

Kott, Jan. 1966. Shakespeare, our Contemporary. Nueva York: W. W. Norton.

Lewis, C. S. 1958. The Allegory of Love. Oxford: Oxford UP.

Shakespeare, William. 1986. Troilus and Cressida, en William Shapespeare, The Complete Works. Ed. de Stanley Wells y Gary Taylor. Oxford: Clarendon Press. 